\title{
Evidence Implementation Plan
}

\author{
Nader Saadeh \\ University of Northampton, Northampton, Northamptonshire, UK \\ Email: nader_abe@yahoo.com
}

How to cite this paper: Saadeh, N. (2019) Evidence Implementation Plan. Journal of Service Science and Management, 12, 315-326.

https://doi.org/10.4236/jssm.2019.123021

Received: February 2, 2019

Accepted: March 29, 2019

Published: April 2, 2019

Copyright (c) 2019 by author(s) and Scientific Research Publishing Inc. This work is licensed under the Creative Commons Attribution International License (CC BY 4.0).

http://creativecommons.org/licenses/by/4.0/

\begin{abstract}
The focus of this paper is to detect the structure of the guest's needs and to discover the best predictor of those needs through using the SERVQUAL method which will lead to a better understanding to the service quality in a five-star hotel in Jordan, and hence, lead to better decision making concerning customer satisfaction. Methodology: The paper used mixed methods. The qualitative approach was used to explore the management's understanding of the guest's perceptions, which is in conducting in-depth, open-ended interviews using semi-structured prompt questions around the management's knowledge about the perceptions of their guests. The quantitative approach focused on the scale model SERVQUAL using a self-administered structured questionnaire which will be presented to the hotel's guests. Results and conclusion: Based on empirical evidence and previous studies, this paper reached a point where a benefit for change is actually happening at the end of the research's period using the scale model SERVQUAL. This could be measured through the tools that are mentioned in this research paper.
\end{abstract}

\section{Keywords}

SERVQUAL, Audit, Evidence, Expectations, Perceptions, Customer

Satisfaction, Change

\section{Introduction}

It is essential to know that good decision making depends on sound research. Furthermore, a considerable amount of research knowledge helps managers to reach proper solutions to their problems at the workplace. After all, effective decision making is a process of choosing among several alternatives, and research gets managers to generate effective decisions that resolve their problems [1].

A research audit has been done to investigate the research culture in five-star hotel in Jordan. The findings revealed the understanding of the organisation's (hotel) management in dealing with the "customer satisfaction" problem through 
a systematic process of data gathering and analyses. That is why several aspects of research were existent in the decision-making process that reflected the management's concern about getting to the best decisions in fulfilling their goal of the "customer satisfaction". Consequently, the audit demonstrated the existence of tracking systems, analytical techniques and investigating approaches which were built into the system of decision making of the organisation regarding customer satisfaction. However, the audit detected some deficiencies in the research approach that the organisation follows [2].

\section{Literature Review}

Numerous past studies investigated the role of service quality, which leads to customer satisfaction, in hotels and other service companies through a model named SERVQUAL which was applied in exploring the quality of the service in different kinds of organisations. Reference [3] developed a "22-item instrument" for evaluating customer's perceptions and expectations regarding the service quality being presented in an organisation. This model is a scale which could be used in measuring the perceived quality of the service concerning the customer's perceptions and expectations. Thus, it is a set of structured statements (22-item instrument) that measures the customer's judgment before experiencing the service(expectations) and after experiencing it(perceptions). Those statements formulated a construct of service quality, through Parasuraman's, Zeithaml, and Berry [3] work-study, which was conceptualized, and then operationalised and dimensionalised via a procedure of factor analysis. Evidence of data from four companies checked the scale's validity and reliability.

Oliver, cited in [3] defines satisfaction as follows: "it is a summary psychological state resulting when the emotion surrounding disconfirmed expectations is coupled with the consumer's prior feelings about consumption experience", while "perceived service quality is a global judgment or attitude relating to the superiority of the service" [3]. To illustrate, "satisfaction" is the "emotional reaction following a disconfirmation experience" whereas quality is related to a judgment or attitude. The disconfirmation experience is the difference in the consumer's judgment between his expectations, which are taken before experience, and his perceptions which are after it.

Reference [3] describes the idea of service quality as the comparison of what the consumer expects the firm to offer (expectations), with the actual consumer's perception of the performance of the firm. That is why this scale "SERVQUAL" stems from a set of 97 items, and each item was allocated to consumers in two statements; one for their expectations and the other for their perceptions of the firm. Most of the statements were worded positively, and a seven-point scale was placed after each statement ranging from "strongly agree" to "strongly disagree". In the process of the scale purification first stage and second stage, after the data collection, through a process of data analysis and factor analysis on SPSS software (Statistical Package for the Social Sciences), the 97 items were reduced to 
22-item SERVQUAL instrument statements. Those statements were spread among five dimensions and were used to reflect the expectations and perceptions of the consumers. The SERVQUAL five dimensions suggested the following labels [3]:

“Tangibles: Physical facilities, equipment and appearance of personnel.

Reliability: Ability to perform the promised service dependably and accurately.

Responsiveness: Willingness to help customers and provide prompt service.

Assurance: Knowledge and courtesy of employees and their ability to inspire trust.

Empathy: Caring and individualized attention the firm provides its consumers."

After collecting data and do the factor analysis required to dimensionalise and conceptualize the SERVQUAL construct, Parasuraman, Zeithaml, and Berry [3] did descriptive statistical analysis and regression analysis to detect the best predictor of those dimensions. Similarly, the researcher could measure the service quality of the hotel using this SERVQUAL scale instrument statements in order to capture the existing quality of the hotel's service, the expectations and perceptions of the hotel's customers and understanding of the hotel's management view of those dimensions and how are these related to the hotel's customers.

While Parasuraman, Zeithaml, and Berry [3] explored the service quality in four different service companies: banks, credit card companies, repair and maintenance companies and long-distance telephone company, Akbaba [1] and Markovic and Raspor [4] examined this construct in the hotel industry. Akbaba [5] found out the relation of the SERVQUAL model to the manager's understanding of the customer's need. Likewise, Markovic and Raspor [4] discovered the implementation of the model in the tourism and hospitality industry. Both studies identified the expectations and perceptions of the customers and the dimensions of the service quality construct, while only Akbaba [5] detected the best predictor of those dimensions. Akbaba [5] measured the service quality in a business hotel in turkey. He investigated the expectations of the customers using this model, examines the SERVQUAL model of Parasuraman, Zeithaml, and Berry [3] if it applies internationally, searched for any additional dimensions that suites the hotel industry and must be included in the construct and measured the importance of each dimension in relation to the overall quality of the hotel's customers. However, he found some differences, in his work, in the dimensions and their components from Parasuraman, Zeithaml, and Berry [3] SERQUAL model.

Similarly, Markovic and Raspor [4] measured the perceived service quality using the SERVQUAL model in the Croatian hotel industry. The purpose of their study was to assess its attributes and then determine the factor structure of its perceptions. Data was gathered from fifteen hotels in Croatia using questionnaires. In the same way, descriptive analysis, factor analysis and reliability analy- 
sis were conducted. However, this study lacked a measure of the level of importance of each specific dimension.

While Akbaba's [5] study generated five service-quality dimensions: tangibles, adequacy in service supply, understanding and caring, assurance and convenience, the other study generated four key factors that explained the customers' perceptions of the hotel service. These are reliability, empathy and competence of staff, accessibility and tangibles [4]. To measure expectations and perceptions of the guests Markovic and Raspor [4] prepared 29 service oriented attributes with a seven-point scale that would be presented to a sample of 253 domestic and international guests in the form of self-administered questionnaires. Those attributes were dimensionalised to four factors (mentioned above) through factor analysis using SPSS software. In the same manner, Akbaba [5] used self-administered questionnaires covering a sample of 250 guests using a modified version of the SERVQUAL model of Parasuraman, Zeithaml, and Berry [3] in order to analyze the service quality of the guest's expectations and perceptions in the hotel being studied in Turkey. After reviewing the literature, 29 attributes were developed to be included in the questionnaire of the study. Some attributes were added to capture some aspects related to the hotel industry. Then, after data were collected, factor and reliability analyses were conducted, and descriptive and regression analyses were done to capture the level of importance for every dimension. The key factors were identified (mentioned above).

Consequently, the best predictor in service quality in Turkey's hotel was "tangibles" followed by "understanding and caring" [5]. Thus, in knowing the level of importance, managers can predict what is most important in the structure of the needs of their guests. This helps them to make better decision making and pick up the best of the alternatives available to resolve their problems at the workplace.

For those reasons which were found in previous evidence-based studies, the researcher values the steps of this evidence in measuring the service quality of the audited hotel. Using this evidence: the "SERVQUAL model" with its modifications that were done in the study of Akbaba [5], enables the management to reach a better understanding of service quality of the hotel, and hence better decisions to "customer satisfaction". Therefore the researcher suggests, in a coming section, a strategy project (plan) for researching and measuring the service quality of the hotel using this model-scale which will help managers to determine the best predictors of the service quality construct. Consequently, rational decisions would be taken to the best of the "customer satisfaction", which will be based upon scientific research as a shred of evidence, and this will help to determine the best means to reach this goal.

\section{Methodology}

This research aim is to identify the service quality in the hotel even though it has a moderately-high appetite towards research, as the previous audit revealed [2]. 
It is more beneficial for the management to understand what do they know about the expectations and perceptions of their guests. It is also, most beneficial for the management to understand what are the expectations and the perceptions of their guests. Examples of previous studies were presented in the previous section as evidence of using a scale model that uncovers the hidden needs of the customers. Consequently, this report suggests implementing a research project that aims to detect the structure of the guest's needs and to discover the best predictor of those needs using the suggested scale model SERVQUAL which will lead to better understanding to the hotel's service quality, and hence, to better decision making concerning "customer satisfaction".

So the aim of this research is to detect the structure of the guests' needs in the hotel and to discover the best predictor of those needs. Thus the research question would be "what is the structure of the guests' needs, and what is their best predictor? Hence, to maximize the value of the results in relation to this research question, the paper will focus on multiple methods investigation in order to understand the experiences and the outcomes of the managers and the guests being researched [6]. The exploration of the management's understanding of the guest's perceptions will be based on a qualitative approach. So the aim here is to perceive the management's interpretation of the service quality attributes of guests possible perceptions. The researcher's goal is to reach two objectives, which are: 1) to attempt to reach an interpretive understanding of the management's action so as to arrive at a causal explanation of their course of action [7], and 2) to compare the findings with the guests perceptions of the hotel. Therefore the management will be able to answer these two questions: did they understand what was precisely the guest's perception, given service quality? Moreover, did they know their exact needs? As for uncovering the needs of the guests and detecting the service quality of the hotel according to the expectations and perceptions of the guests, the study will depend upon the quantitative approach. The researcher will follow the SERVQUAL scale model steps which were conducted in Akbaba's [5] study.

\subsection{Qualitative Approach}

This part will conduct one in-depth, open-ended interview using semi-structured prompt questions around the management's knowledge about the perceptions of their guests. The questions will be structured around the attributes that were used in Akbaba's [5] study. Four managers will be selected depending upon their seniority, and their closeness to the tracking and investigation of "customer satisfaction" issue and will be interviewed in a focus group approach. Using this approach will do more than just repeated single interview for every manager can do, in covering the hidden views of those involved in this study [8]. Hence, those managers would be the General Manager, the Food and Beverage Manager, the Marketing Manager and the Area Quality and Continuous Improvement Manager. The semi-structured prompt questions may lead to other sub-questions [7], 
these are:

1) Could you describe if the hotel's appearance, facilities, equipment and food and beverage are proper, appealing, modern and adequate for your clients?

2) In your own words, how would you identify the adequacy in service supply in the hotel's client view?

3) How would you see the employees' empathy for the hotel's guests in their view? Why?

4) How would you understand the guest's view of the hotel's security, safety, and hotel's operating hours and the employees' confidence in their guests?

5) How do you think of the guest's access to the hotel, information and complaints?

Those questions will be asked in a recorded focus group approach [8] with the researcher being the moderator of the interview; then the recorded audio will be transcribed. The focus group will formulate a committee. Thematic analysis will be conducted on the transcript, and the main themes and sub-themes will be extrapolated. The findings will be presented and discussed with the focus group committee showing their interpretive understanding of the guests' perceptions, and then to be compared with the results of the quantitative study of the questionnaires discussed below.

\subsection{Quantitative Approach}

A self-administered structured questionnaire, taken from Akbaba's [5] study, will be presented to the hotel's guests (see questionnaire attributes below). A sample size of 250 questionnaires will be presented to the guests once on their check-in to measure their expectations, and once on their check-out to measure their perceptions. The sample size was chosen due to its reliability and due to its similar usage in previous studies [5]. Likewise, the questionnaires will be divided into three parts: 1) the part that measures the expectations and perceptions, 2) the part that measures the overall quality and 3) the part that contains descriptive data of the sample. The first part will be presented to the guests on their check-in showing the attributes that were used in Akbaba's [5] study (see questionnaire attributes below) with a five-point Likert scale ranging from (1) "very low" to (5) "very high" for measuring their expectations of the service quality. On their check-out, the same questionnaire format will be presented to the same guests that were studied at their check-in; this time to measure their perceptions. The second part will measure the overall quality of the service by asking this question on the guest's check out "Overall, how would you rate the quality of the service you received in this hotel?" [5] The third part, as mentioned, will ask questions related to socio-demographic data. Descriptive analysis will be conducted using the "Statistical Package for Social Sciences" IBM SPSS statistics version 22, showing the mean and standard deviation of the data. Accordingly, the difference of the two means (perceptions "PM" expectations "EM") will be calculated to show the level of satisfaction of the guest and paired t-test will be 
carried out to test its significance. If the result of the difference was negative; this shows a low (or negative) level of satisfaction, and if it is positive; this shows a definite level of satisfaction. Factor analysis will be performed to explore the dimensionality of the 29 attributes, and to decide on the dimensions (parameters) of the regression analysis that will be done to determine the level of importance of each dimension. Hence, in determining the level of importance, the management will be able to focus on the best predictor of the quality dimension which will reflect positively on satisfaction. A reliability test of the scale will also be performed since a reliable scale indicates the stability and consistency of it [1]. In order to track service quality trends within the hotel's guests, this scale will be conducted periodically [3]. Thus the SERVQUAL scale will be administered twice a year (every six months) for two years.

\subsection{Questionnaire Attributes [1]}

- The hotel has visually appealing buildings and facilities.

- The service units of the hotel have adequate capacity (dining rooms, meeting rooms, swimming pools, business centre facilities).

- The hotel has modern-looking equipment (air conditioner, furniture, elevator, communication devices).

- The atmosphere and equipment are comfortable and appropriate for stay (beds, chairs, rooms, comfortable, clean, and tranquil).

- The equipment of the hotel works properly without causing breakdowns.

- Materials associated with the services are adequate and sufficient (soap, shampoo, and towel).

- Food and beverages served are hygienic, adequate, and sufficient.

- Employees of the hotel appear neat and tidy (as uniforms and personal grooming).

- The hotel provides the services as they were promised.

- The hotel performs the services right the first time.

- Employees provide prompt service.

- The hotel provides the services at the time it promises to do so.

- Employees are always willing to serve customers.

- Employees are always available when needed.

- The hotel keeps accurate records (reservations, guest records, bills, orders).

- The hotel resolves guest complaints and compensates for the inconveniences guests suffer.

- The hotel provides flexibility in services according to guest demands.

- The hotel serves consistent services (providing the same services and associated materials every time).

- Employees have the knowledge to provide information and assistance to guests in areas they would require (shopping, museums, places of interest).

- Employees always treat guests in a friendly manner.

- Employees of the hotel understand the specific needs of guests. 
- The hotel is also convenient for disabled guests (necessary arrangements made for the disabled).

- Employees give guests individualized attention that makes them feel special.

- The hotel and its facilities have operating hours convenient to all their guests.

- The hotel provides its guests with a safe and secure place.

- Employees are still confidence in guests.

- Employees have in-depth occupational knowledge (professional skills, foreign language, communication skills).

- It is easy to access the hotel (transportation, loading and unloading area, car parking area).

- Getting information about the facilities and services of the hotel is easy.

\section{Strategy Project (Plan)}

One way of keeping track of the research plan is to put it in bar charts. Gantt charts, which are also recognized as bar charts, are known after their originator Henry Gantt (1861-1919) and used widely in project management. It is a way of keeping track of the research project visually so it may be a powerful aid to control it [9]. Table 1 lists the main tasks that this plan will carry out and Table 2 is the resulting bar chart (Gantt chart) from Table 1, first stage [9]:

Then the same procedure will be repeated in the same way for the $3^{\text {rd }}$ and the $4^{\text {th }}$ stages in Table 4 and Table 5.

The last three tables show that the second stage ends in the $32^{\text {nd }}$ week, the third stage ends in the $56^{\text {th }}$ and the $4^{\text {th }}$ in the $80^{\text {th }}$ week.

\section{Resources and Evaluation of Change}

It is important dto determine the sources of information, cost and resources of a research project to be able to implement this project and to develop an evaluation procedure to measure change [10]. It is also crucial that the results of this research project end to a beneficial change in the procedures that the management takes in getting to the best customer satisfaction outcomes. Moreover, evaluation and measurement of change is a powerful tool to identify the impact of this change on the understanding of the hotel's service quality and customer satisfaction. Below one can find the pre-assumed recourses, sources of information, and cost of this project and the main points that illustrate the measurement and evaluation of change as follows:

1) Sources of information will be from: a) questionnaires distributed by front desk staff or duty manager and guests who will answer the questionnaires in the quantitative part, and b) audio recorder and management committee in the qualitative part.

2) Resources will be the researcher, the researcher's computer with SPSS and Nvivo installed on it, MP3 audio recorder, the staff of front desk or the duty manager, participants (guests), management committee and printed questionnaires form paper which can be provided from the hotel. 
Table 1. List of main plan tasks.

\begin{tabular}{|c|c|c|c|}
\hline Number & Activity Description & $\begin{array}{l}\text { Duration in } \\
\text { (days) }\end{array}$ & $\begin{array}{c}\text { Preceding } \\
\text { activities }\end{array}$ \\
\hline 1 & $\begin{array}{l}\text { Preparing for the qualitative materials required } \\
\text { to conduct the qualitative study (typing the } \\
\text { semi-structured questions and preparing } \\
\text { the mp3 audio recorder). }\end{array}$ & 1 & \\
\hline 2 & $\begin{array}{l}\text { Preparing for the quantitative materials required to } \\
\text { conduct the quantitative study (questionnaires). }\end{array}$ & 2 & \\
\hline 3 & Call for setting an appointment & 1 & 1 \\
\hline 4 & Confirm the date & 1 & 3 \\
\hline 5 & Focus group interview & 1 & 4 \\
\hline 6 & Transcribe the recorded audio & 3 & 5 \\
\hline 7 & Analyze the transcription & 3 & 6 \\
\hline 8 & $\begin{array}{l}\text { Dissemination of findings in a report in a } \\
\text { meeting with the committee after getting } \\
\text { the results of the quantitative study }\end{array}$ & 1 & \\
\hline 9 & $\begin{array}{l}\text { Preparing for the quantitative study } \\
\text { (calling for preparation) }\end{array}$ & 1 & 2 \\
\hline 10 & $\begin{array}{l}\text { First stage: presenting self-administered } 250 \\
\text { questionnaires on the arrival of guests for } \\
\text { capturing guests' expectations. Random } \\
\text { selection of the guests will be advised. }\end{array}$ & & 9 \\
\hline 11 & $\begin{array}{l}\text { Presenting the same format questionnaires } \\
\text { for the same guests upon their departure } \\
\text { for capturing guests' perceptions. }\end{array}$ & 30 & 10 \\
\hline 12 & Entering the data from the questionnaires on SPSS. & 10 & 11 \\
\hline 13 & $\begin{array}{l}\text { Analyzing the data: factor analysis, } \\
\text { reliability analysis, regression analysis. }\end{array}$ & 7 & 12 \\
\hline 14 & $\begin{array}{l}\text { Dissemination of results with management } \\
\text { committee in a meeting. Comparing } \\
\text { with qualitative findings. }\end{array}$ & 1 & 13,7 \\
\hline 15 & $\begin{array}{l}\text { Second stage after six months: presenting } \\
\text { self-administered } 250 \text { questionnaires on the arrival } \\
\text { of guests for capturing guests' expectations. Random } \\
\text { selection of the guests will be advised. }\end{array}$ & & 14 \\
\hline 16 & $\begin{array}{l}\text { Presenting the same format questionnaires } \\
\text { for the same guests upon their departure } \\
\text { for capturing guests' perceptions. }\end{array}$ & 30 & 15 \\
\hline 17 & Entering the data from the questionnaires on SPSS. & 10 & 16 \\
\hline 18 & $\begin{array}{l}\text { Analyzing the data: factor analysis, } \\
\text { reliability analysis, regression analysis. }\end{array}$ & 7 & 17 \\
\hline 19 & $\begin{array}{l}\text { Dissemination of results with management } \\
\text { committee in a meeting. Comparing with } \\
\text { qualitative findings and past quantitative results. }\end{array}$ & 1 & $18,13,7$ \\
\hline 20 & $\begin{array}{l}\text { The third stage after six months: } \\
\text { (same procedure) }\end{array}$ & & 19 \\
\hline 21 & $\begin{array}{l}\text { The fourth stage after six months: } \\
\text { (same procedure) }\end{array}$ & & 20 \\
\hline
\end{tabular}


Table 2. First stage.

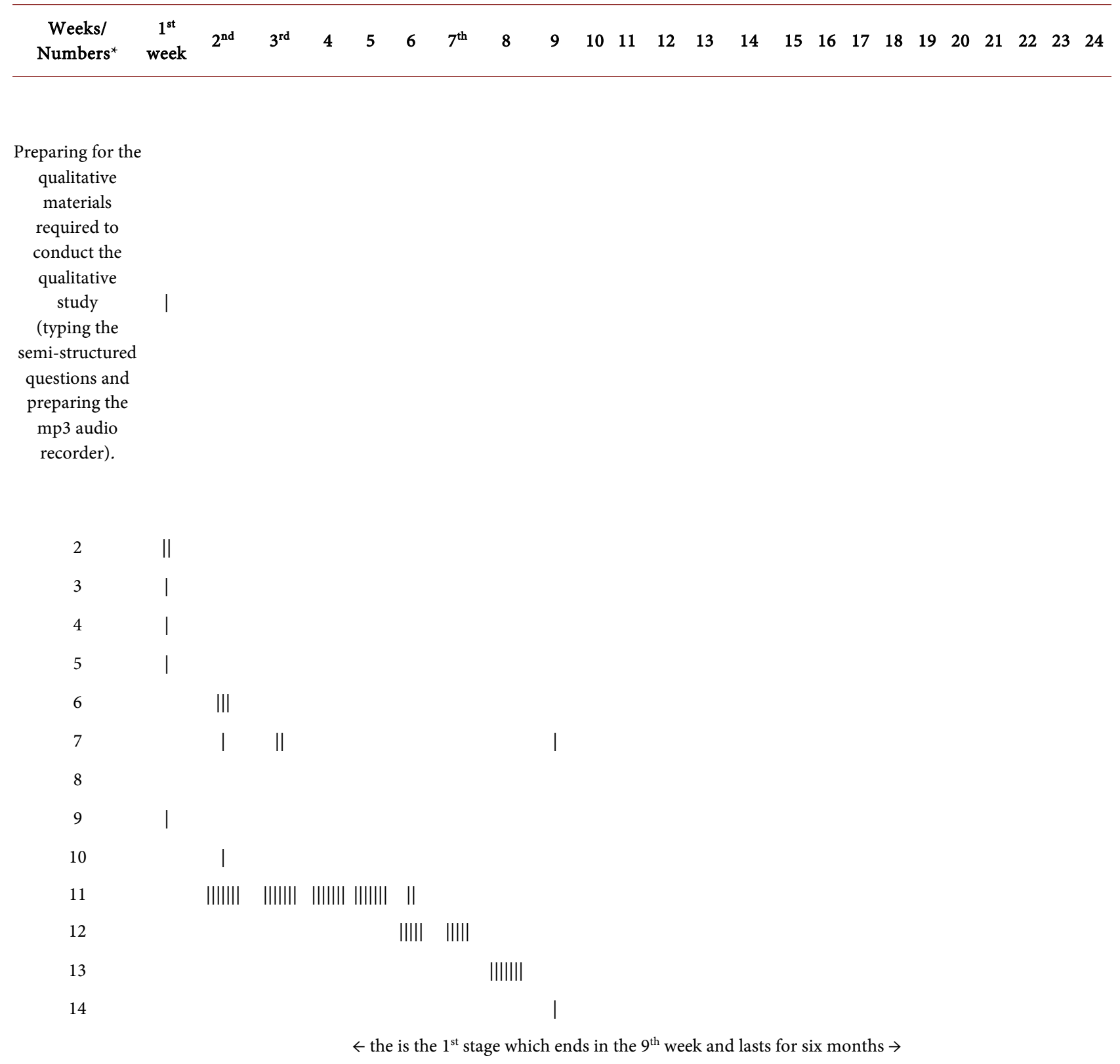

${ }^{*}$ The numbers are for the first column in Table 1 and reflect the activity description. The chart is for six months and divided to 24 weeks, which means it is for the first stage. Table 3 is the continuing bar chart (Gantt chart) from Table 1 second stage.

Table 3. Second stage.

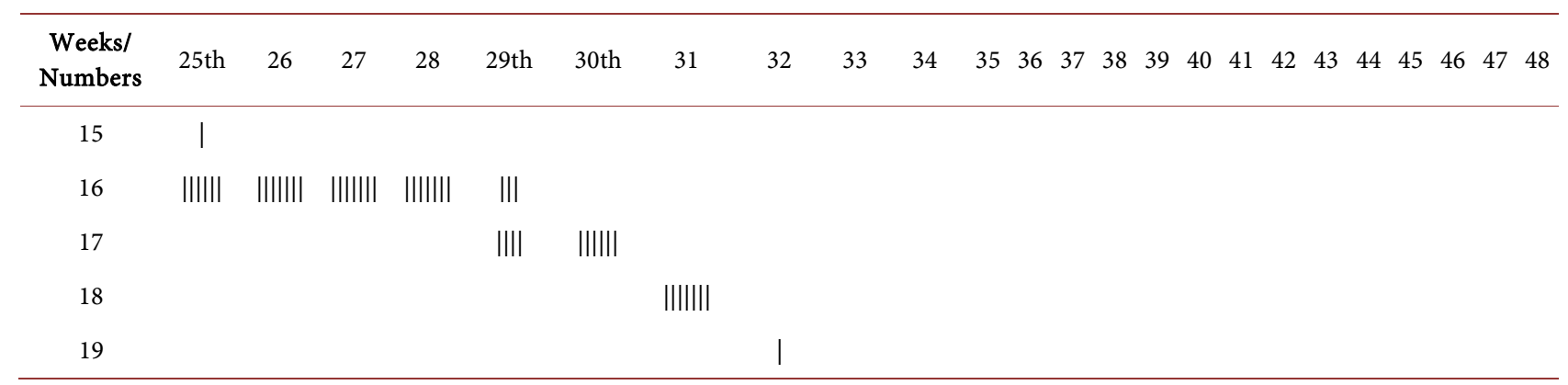


Table 4. The $3^{\text {rd }}$ stage.

\begin{tabular}{|c|c|c|c|c|c|c|c|c|c|c|}
\hline Weeks/Numbers & 49th & 50 & 51 & 52 & 53 & 54 & 55 & 56 & $\ldots$ & 72th \\
\hline 20 & | & & & & & & & & $\ldots$ & \\
\hline $20 \mathrm{a}$ & |||||| & ||||||| & ||||||| & $|\|||| \mid$ & $\| \mid$ & & & & $\ldots$ & \\
\hline $20 \mathrm{~b}$ & & & & & \|\| $\mid$ & |||||| & & & $\ldots$ & \\
\hline $20 c$ & & & & & & & |||||| $\mid$ & & $\ldots$ & \\
\hline $20 \mathrm{~d}$ & & & & & & & & | & $\ldots$ & \\
\hline
\end{tabular}

Table 5. The $4^{\text {th }}$ stage.

\begin{tabular}{|c|c|c|c|c|c|c|c|c|}
\hline Weeks/Numbers & 73th & 74 & 75 & 76 & 77 & 78 & 79 & 80 \\
\hline 21 & | & & & & & & & \\
\hline $21 \mathrm{a}$ & $\||||| \mid$ & |||||||| & |||||||| & |||||||| & III & & & \\
\hline $21 \mathrm{~b}$ & & & & & |||| & |||||| & & \\
\hline $21 \mathrm{c}$ & & & & & & & |||||| $\mid$ & \\
\hline $21 \mathrm{~d}$ & & & & & & & & | \\
\hline
\end{tabular}

3) Cost of this research will be only the contract fee of this research project which will be agreed upon later.

4) (PM-EM) is a measuring tool to evaluate change which happens during the period of research. It will be done every six months.

5) Determining the predictors, every six months, is a measuring tool to the best predictors of the hotel's service quality.

6) Evaluating the management's vision of guest perceptions from the qualitative study. If it is different; suggestions would be made to shift their view towards the best predictor of service quality.

7) Preparing for training programs for employees interacting with guests while focusing on the $1^{\text {st }}$ and the $2^{\text {nd }}$ predictors, and illustrating the level of importance of the service quality dimensions.

8) Repetition the SERVQUAL procedure every six months to reveal any changes happening in (PM-EM) and in predictors to track trends, since the periodic implementation of SERVQUAL discovers trends [3].

9) Observing if there is any decrease in problems from the Problem Tracker over time.

10) The shift will be measured from the change in (PM-EM). The change in predictors will measure the change in trends. A change in policies must follow any change in those measuring tools.

\section{Conclusion}

The research aims to reach a point where a benefit for change is actually happening at the end of the research's period. This could be measured through the tools that are mentioned above. Thus if (PM-EM) was negative and a shift in the training procedures and the management's policies had an impact on service 
quality that shifted (PM-EM) to a positive figure, then this indicated a definite beneficial change that would positively impact the customer satisfaction. Also, if the results of the predictors show any change in trends in service quality, then a change in the training programs and policies would follow this change to be able to get to the best of customer satisfaction. If (PM-EM) was positive from the start or in the middle of the period, then using SERVQUAL as a tracking tool is beneficial for keeping it this way. This study has identified a benefit for change based on empirical evidence and previous studies. But for further studies there is a need to be investigated using the same scale model in the food and beverage department. As this hotel has multiple food and beverage facilities which have a high contribution in the operational income structure. Hence resembling study in this department would add a high value to the customer satisfaction knowledge in those areas.

\section{Conflicts of Interest}

The author declares no conflicts of interest regarding the publication of this paper.

\section{References}

[1] Sekaran, U. (2003) Research Methods for Business: A Skill Building Approach. $4^{\text {th }}$ Edition, John Wiley and Sons Inc., Southern Illinois.

[2] Saadeh, N. (2018) Research Culture Audit. The University of Northampton, 1-27. (Unpublished)

[3] Parasuraman, A., Zeithaml, V.A. and Berry, L.L. (1988) SERVQUAL: A Multiple-Item Scale for Measuring Consumer Perceptions of Service Quality. Journal of Retailing, 64, 12-40.

[4] Markovic, S. and Raspor, S. (2010) Measuring Perceived Service Quality Using SERVQUAL: A Case Study of the Croatian Hotel Industry. Management, 5, 195-209.

[5] Akbaba, A. (2006) Measuring Service Quality in the Hotel Industry: A Study in a Business Hotel in Turkey. International Journal of Hospitality Management, 25, 170-192. https://doi.org/10.1016/j.ijhm.2005.08.006

[6] Schutt, K.R. (2015) Why Use Mixed Methods? Your Questions Are Answered. Sage Publishing, Thousand Oaks.

https://connection.sagepub.com/blog/industry-news/2015/02/11/why-use-mixed-m ethods-your-questions-answered/

[7] Bryman, A. and Bell, E. (2011) Business Research Methods. $3^{\text {rd }}$ Edition, Oxford University Press, Oxford.

[8] Flick, U. (2009) An Introduction to Qualitative Research. $4^{\text {th }}$ Edition, Sage Publications, Thousand Oaks.

[9] Lock, D. (2014) The Essentials of Project Management. $4^{\text {th }}$ Edition, Routledge, ProQuest E-Book Central.

[10] Anon (2015) Project Planning and Evaluation. https://www.Publicsafety.gc.ca/cnt/cntrng-crm/crm-prvntn/tls-rsrcs/prjct-plnnng-e $\underline{\text { n.aspx\#a05 }}$ 